\title{
New Approach of Using Structural Modelling for Personalized Study Planning
}

\author{
Raita Rollande* \\ Engineering Research Institute \\ "Ventspils International Radio \\ Astronomy Centre" of Ventspils \\ University College, \\ Ventspils, Latvia
}

\author{
Janis Grundspenkis \\ Department of Systems Theory and \\ Design, \\ Riga Technical University*, \\ Riga, Latvia
}

\author{
Antons Mislevics \\ Department of Systems Theory and \\ Design, \\ Riga Technical University, \\ Riga, Latvia
}

\begin{abstract}
The planning of individual studies becomes more and more topical. Alongside the fast and diverse rhythm of life, people need individual approach to study planning. It ensures wider availability of learning for different social groups. The use of information and communication technologies (ICT) in the process of studies makes it more attractive and more interesting as well as more adequate to the demands of the $21^{\text {st }}$ century. The authors have developed graph based framework for personalization of education process based on the set of four graphs representing the structure of the study programme, the structure of the study courses, the concept maps, and the learning objects $[1,2,3,4,5]$. Special tool is needed which allows the learners themselves to design the learning strategy corresponding to their interests. The authors had already implemented personalized study planning process in a prototype, which allows to create a personalized study programme, and then to plan the course learning, setting the courses in the required sequence $[3,4,5]$. In this paper the authors propose the use of the methods of structure analysis to calculate the ranks for the node of the graphs thus detecting the most significant nodes in the graph structure. The calculations for the ranks are made for the graph of the study programme, for the graph of study courses, and for the concept maps. The calculation of ranks for the graph nodes allows detecting the most significant courses in the study programme, the most important topics in the study course and the most essential concepts in the concept map.
\end{abstract}

Keywords-intelligent tutoring system; personalized education; graphs; structural modelling; element ranking and structural analysis

\section{INTRODUCTION}

According to the analysis of the planning documents of the field of education $[7,8,9,10,11]$ there is need for the educational system that offers individual approach to the learner. The researched documents of planning showed that the learner should be ensured by larger variety of study forms and more personalized studying to satisfy the need for new competences and skills. The full-time forms of training do not always correspond to the learner's demands because he/she has individual demands and interests for studies as well as different skills, background knowledge, learning style, and besides the learner very often studies same time working. The use of ICT in the process of studies has significant role as it offers electronic study materials. ICT can be used as additional tools in the organization of classes, in creation of study materials, in knowledge assessment, in communication, and so on. ICT allow to make the studying process more attractive and interesting as well as more adequate to the demands of the $21^{\text {st }}$ century [12]. The use of ICT in studies and for storage the electronic materials is ensured by computerized studying systems which offer to the learner to study in the environment that does not depend on time and place. However, it should be mentioned that computerized studying systems do not ensure individual approach. Thus it is necessary to have such studying systems which implement personalized learning and it starts with creation of individual study plan according to the learner's wishes and needs. Personalized learning can be carried out in two ways: the lecturer cooperates with the learner individually or there is developed intellectual learning system. The authors had already implemented graph-based framework for personalization of education process. There are used graphs to represent the structure of the personalized study planning framework. Those allow not only showing the structure in a transparent way, but also allow using the methods of structure analysis to calculate the ranks for the nodes of the graphs thus detecting the most significant node in the graph structure. In this paper, the authors perform study programme and course structure graph analysis using such structural modelling method as calculating ranks.

The paper is organized as follows. The next part is the existing personalized learning construction systems. The third section presents Graph based framework for personalization of education process. The fourth section shows personalized study planning system's SPS prototype. The fifth section describes SPS analysis using structure modelling methods. The sixth section describes graph structure analysis. The paper concludes with a short summary and it outlines directions for the future research.

\section{PERSONALIZED LEARNING CONSTRUCTION SYSTEMS}

This chapter is devoted to the existing personalized learning construction systems.

Kabicher and Motschnig-Pitrik [13] have elaborated the tool for study programme visualization using the CEWebS (Cooperative Environment Web Services) platform, which is designed to visual description of study programme using the graph. CEWebS is intended only for teachers; the learners cannot work with it independently. Besides the study programme showed in the system is static not dynamic, i.e., all have only one tutoring scenario. 
Gestwicki [14] and Toombs [15] elaborated the tool for visualisation of the study programme CurricVis. The tool automatically generates the study programme as oriented graph based on information present in the knowledge basis. CurricVis is the design of the programme that presents the structure of the study programme in a form of graph. In comparison with the previous tool, CurricVis allows to be operated not only by the designers of the study programme but also by learners themselves thus enabling them to participate in the study programme planning process. CurricVis tool does not have an interactive graph creation mode.

Zucker in the article [16] offers the tool ViCurriAS that includes two modules. Study programme module is for the design and the modification of the study programme. The module allows the faculty methodologists and consultants arrange the courses in the study programme and define the prerequisitions of these courses. The Consultation module allows the consultants to enter the marks or planning information in the same graph that was created in the Study programme module. ViCurriAS system same as the two previously described systems does not offer to the learner him/herself to create the study programme dynamically neither realizes further training processes.

A different approach from the previously described tools is offered by Auvinen [17], unlike the previously described systems this system has described relationship not between the study courses but between study outcomes. He offers the design of study programme using the graphs of study outcomes. The construction of the study programme is based on choice of competences. According to the chosen competences the graph of acquirable study courses relating to study results is created. In this system the learner is able to design his/ her own study programme. As negative trend should be regarded the thing that the learner may ignore topics that are related to study outcomes which are not related to his/her competences.

Nkambou, Gauthier and Frasson [18, 19, 21, 21] offer the tool CREAM for designing the study programme. The study programme creation environment allows automatically generate the study programme. The course creation environment allows to create courses with the given parameters. At the basis of CREAM tool study programme is the module of skills. The learner chooses the acquirable skills and after that CREAM tool generates suitable study programme. In CREAM tool as in previous tools study courses are described in the form of graph.

As existing personalized study planning systems do not ensure the learner to create personalized study plans and courses within one system it is necessary to have supplements in the pedagogical module that support personalized learning allowing the learner him-/her-self design the study plan suitable to one's needs, see the topics of the study course and choose the sequence of study course acquisition, get acquainted with concept connection and choose learning objects of topics.

According to the analysis of the study system architecture, there follows such demands for the new architecture:
- develop a united system which allows to personalize the study process beginning with design of study programme plan to its acquisition;

- describe the study programme, study courses, topics, concepts and learning objects;

- include the possibility for the learner to personalize the study process allowing to develop the individual study plan, set the sequence of course acquisition, frame the concept map and choose the learning objects for acquisition of topics and concepts;

- the structure of study programmes, study courses, concepts and learning objects displayed in the graph mode;

- study courses and course topics define the range of prerequisites and restrictions so that the learner himself could develop individual study programme plan and set the sequence of topic acquisition;

- offer the designing of study programme plan for lifelong learning courses;

- ensure the designing of study programme plan taking into account that the learner can participate in mobility programme or study after moving from another study programme, or after the acknowledgment of credit points;

- offer several types for study programme, study course, concepts and learning object graph visualization so that the learner could get transparent structure of study programme or study course with different amount of nodes;

- include the determination of significance of graph nodes in order to help the programme directors and teachers manage the structure of study programme and course as well as to help learners in planning personalized studies.

The next chapter describes the graph based framework for personalization of education process, which consists of four graphs.

\section{GRAPH BASED FRAMEWORK FOR PERSONALIZATION OF EDUCATION PROCESS}

The previous chapter described different learning systems which allow to develop study programmes and courses to achieve personalized study planning. Rather seldom there are systems which allow the learner to design both the study progamme plan and courses, but there are no systems at all [3], which allow to fulfill the whole learning scenario beginning with the designing of the study programme plan and ending with the choice of learning objects for each concept and topic be learned as well as defining the most important courses, topics and concepts. As the result in the previous chapter there are defined demands for the development of such individual learning system. In this chapter there is offered the framework of personalized study planning which is based on the set of graphs. 
To fulfill the personalized study planning from creation of study programme plan to the choice of learning objects, there is developed the framework of personalized study planning based on the following set of graphs (Fig. 1) [1, 2, 3, 4, 5]:

- a graph representing a conceptual structure of study program $\mathrm{G}_{1}\left(\mathrm{~V}_{1}, \mathrm{Q}_{1}\right)$ allows to design individual study program;

- a graph representing study course $\mathrm{G}_{2}\left(\mathrm{~V}_{2}, \mathrm{Q}_{2}\right)$ allows to develop individual learning scenario;

- a graph visualizing each topic using concept map $\mathrm{G}_{3}\left(\mathrm{~V}_{3}, \mathrm{Q}_{3}\right)$ ensures mapping of each topic to the corresponding concept map;

- a graph representing learning objects $\mathrm{G}_{4}\left(\mathrm{~V}_{4}, \mathrm{Q}_{4}\right)$ describes each concept with learning objects.

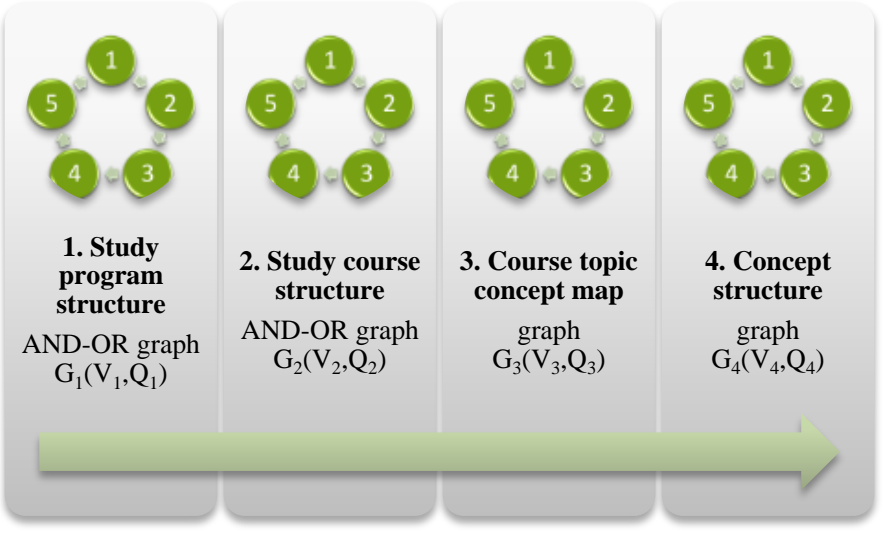

Fig. 1. Graph based framework for personalization of education process [3]

The graphs of personalized study planning framework are related. Each next graph results from the previous. Graph $\mathrm{G}_{1}$ allows the learner to create personalized study programme choosing the courses to be included into one's individual study programme. After creation of study programme the learner chooses the study courses which he/she wants to master. To describe the course structure is meant graph $\mathrm{G}_{2}$, which shows the topics that are included in each study course. To master the topics of the study course the next level of detail uses graph $\mathrm{G}_{3}$, which describes the concepts of each topic and their mutual relationship. Finally the fourth and the concluding graph of the study planning framework allows the learner to personalize mastering of each topic or concept by choosing the learning objects, and that corresponds graph $\mathrm{G}_{4}$.

To use the personalized study planning framework the following steps should be fulfilled for the development of personalized study planning framework (Fig. 2):

- Step 1 - at first graph $\mathrm{G}_{1}$ is designed and it starts with definition of study programme which is the node of the graph $\mathrm{G}_{1}$ root;
- Step 2 - in the next level are defined the study years which are the direct successors of the root node;

- Step 3 - in the next level for each study year adjust two successor nodes - spring semester and autumn semester;

- Step 4 - for each semester in the next level of graph $\mathrm{G}_{1}$ define successor nodes which correspond to the tittle of the study programme part;

- Step 5-for each study programme part in the next level as the nodes of successors define respective tittles of the study courses;

- Step 6 - for each course tittle as predecessors describe tittles of other courses which are prerequisites for mastering the course;

- Step 7 - start to design graph $\mathrm{G}_{2}$ and define the study course tittle and its ECTS volume which is one of the graph $\mathrm{G}_{2}$ root nodes. The number of $\mathrm{G}_{2}$ corresponds to the number of course tittles described in graph $\mathrm{G}_{1}$;

- Step 8 - define for the study course node the successor nodes - numbers of the classes, their number corresponds the volume of credit points, one ECTS is 12 classes, one class is 2 academic hours;

- Step 9 - for each number of the class in the next level of the graph successor nodes define the tittles of the topics which are mastered in definite class;

- Step 10 - for each topic tittle define predecessors which are shown with the predecessors' node and which shows the tittles of the prerequisite topics;

- Step 11 - choose the tittle of the topic and define its concepts which correspond graph $\mathrm{G}_{3}$, as the result the number of graphs $\mathrm{G}_{3}$ corresponds the number of topics;

- Step 12 - relate the concepts with links and define the semantics of the links;

- Step 13 - choose the tittle of the topic from graph $\mathrm{G}_{2}$ or concept from graph $\mathrm{G}_{3}$, which is the node of the root of graph $\mathrm{G}_{4}$. The number of graphs $\mathrm{G}_{4}$ corresponds the number of topics of graph $\mathrm{G}_{2}$ or the number of concepts of graph $\mathrm{G}_{3}$;

- Step 14 - for each root node of graph $\mathrm{G}_{4}$ in the next level as successors' node define the tittles of learning objects;

- Step 15 - for each tittle of the learning object define learning objects. 


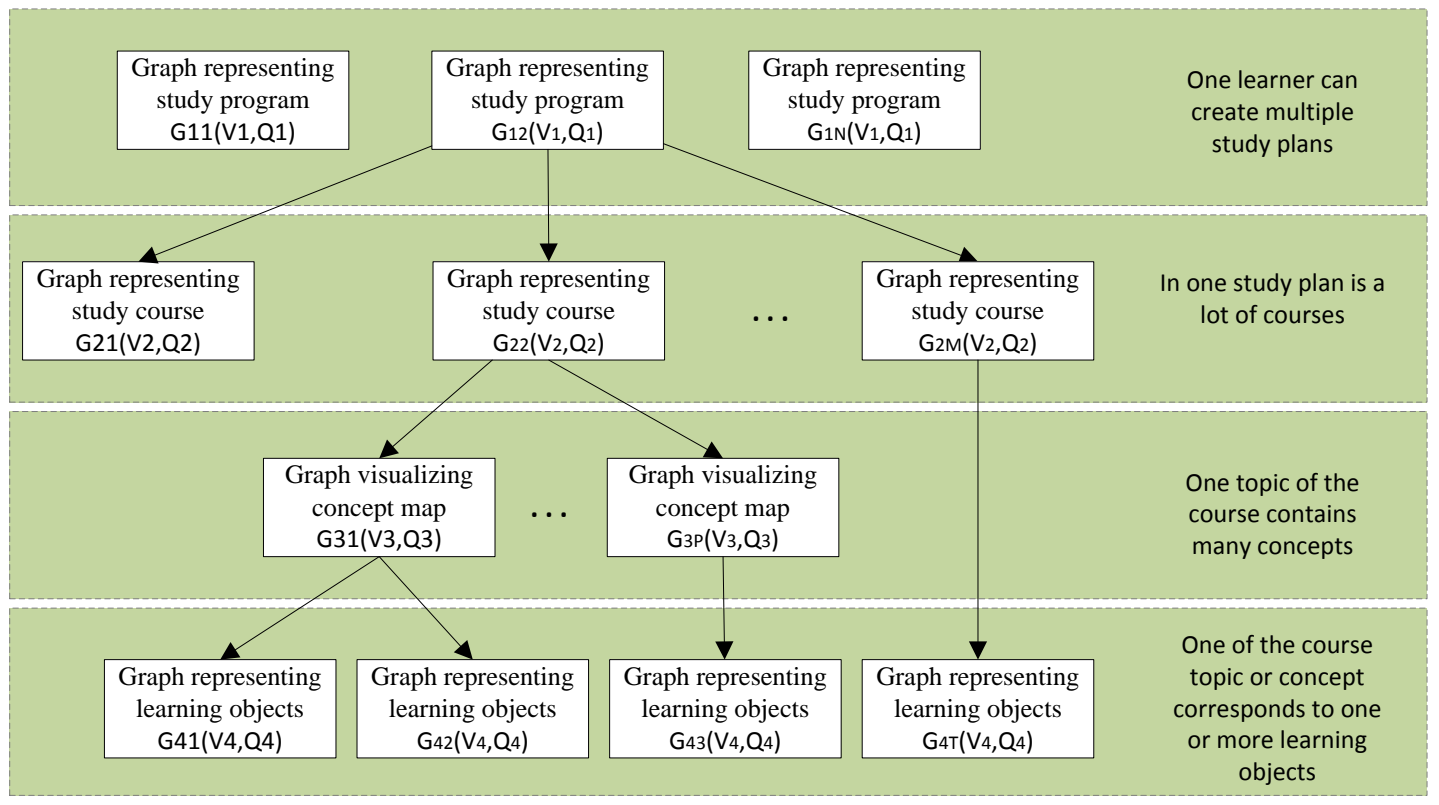

Fig. 2. General structure of personalized study planning framework

This framework allows any student to tailor a study programme by adapting the modularized curriculum structure and to choose the suitable learning strategy for each study course. Next section describes personalized study planning system prototype SPS.

\section{Personalized Study Planning System SPS PROTOTYPE}

The previous section describes the concept of ITS - graphbased framework for personalization of education process. This section describes developed personalized study planning system's SPS prototype.

In SPS prototype is implemented system data basis $(S P S D B)$, data view and insert forms (SPS.DataManager) and study programme construction software application (SPS.StudentStudyProgramBuilder). SPS prototype has been elaborated using Microsoft .NET Framework 4.5 software creation platform [22, 23]. There are used such built-in technologies as:

- Windows Presentation Foundation (WPF) [24] - for creation of graphic user interface;

- LightSwitch [25] - for creation of data review and types of input.

SQL Server 2012 Express LocalDB [26] is used as the system of database management for the local database. It simplifies the installation of prototype because there is no need to install and configure the database server. As SPS does not use specific possibilities of SQL Server 2012 Express LocalDB the solution can be used also for other versions of $S Q L$ Server [27].

The prototype was elaborated using the programme creation tool Visual Studio 2012 [28]. Implementing the operations with graphs and graph visualizations open code software libraries QuickGraph [29] and Graph\# [30] are used.
Fig. 2 shows the components of the prototype describing also the technologies used in their implementation.

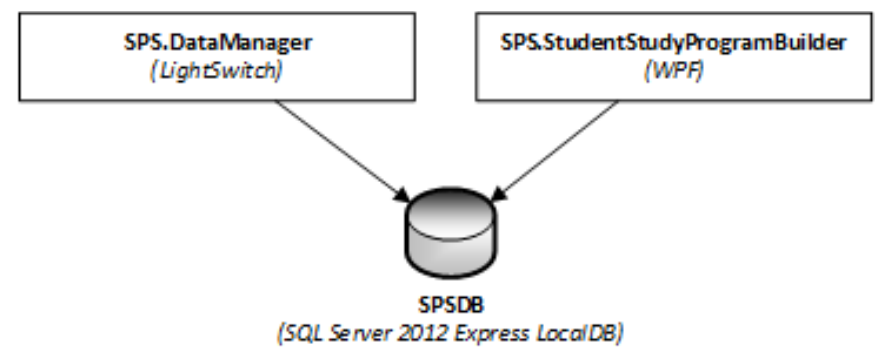

Fig. 3. SPS architecture $[4,5]$

Personalized study planning system SPS prototype contains two tools $[4,5]$ :

- SPS.DataManager, which is provided to input data on study course field, study programme, parts of the study programme, teachers, courses, the structure of course topics, course topics and learners, and student study programmes in order to fulfil personalized tutoring (shown in Fig. 4);

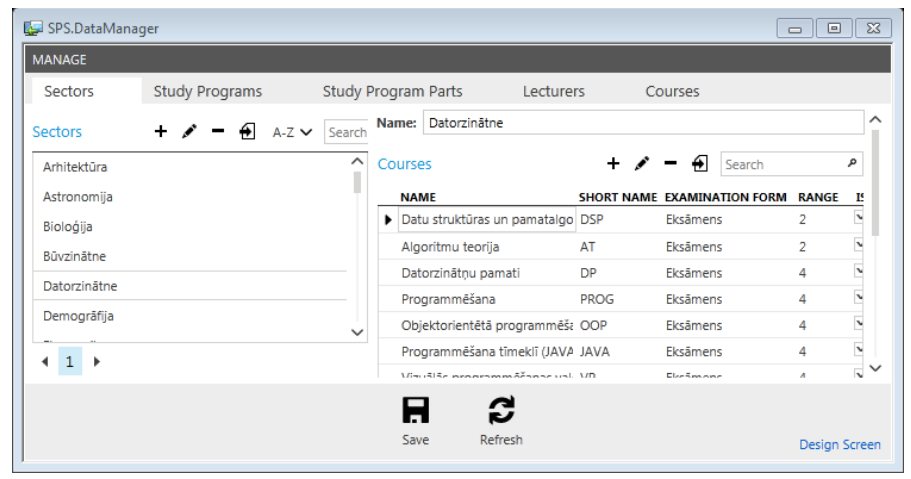

Fig. 4. SPS DataManager $[4,5]$ 
- SPS.StudentStudyprogramBuilder, which is provided to determine personalized study programme (see Fig. 5) and the sequence of acquisition of study course topics (see Fig. 6).

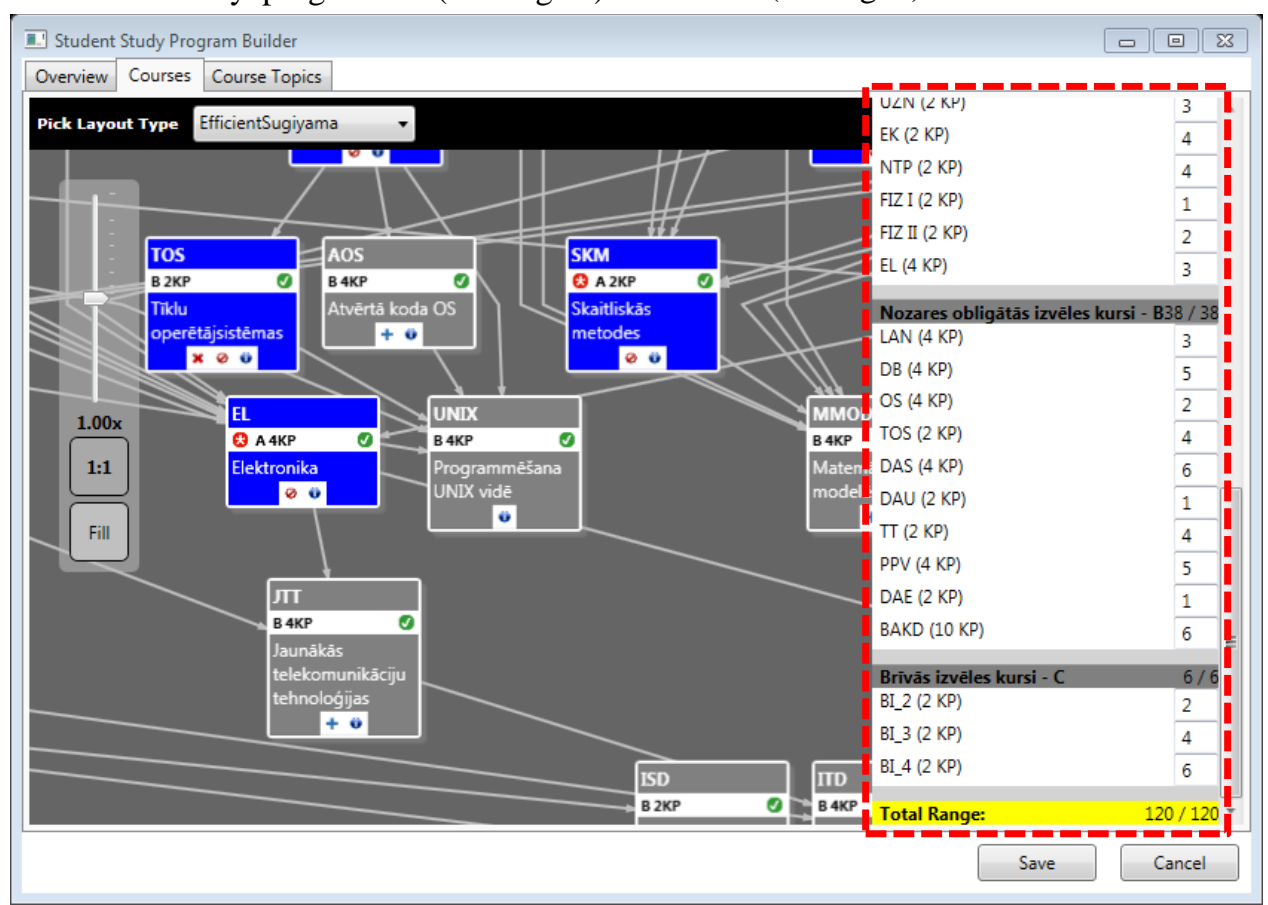

Fig. 5. SPS.StudentStudyprogramBuilder personalized study programme

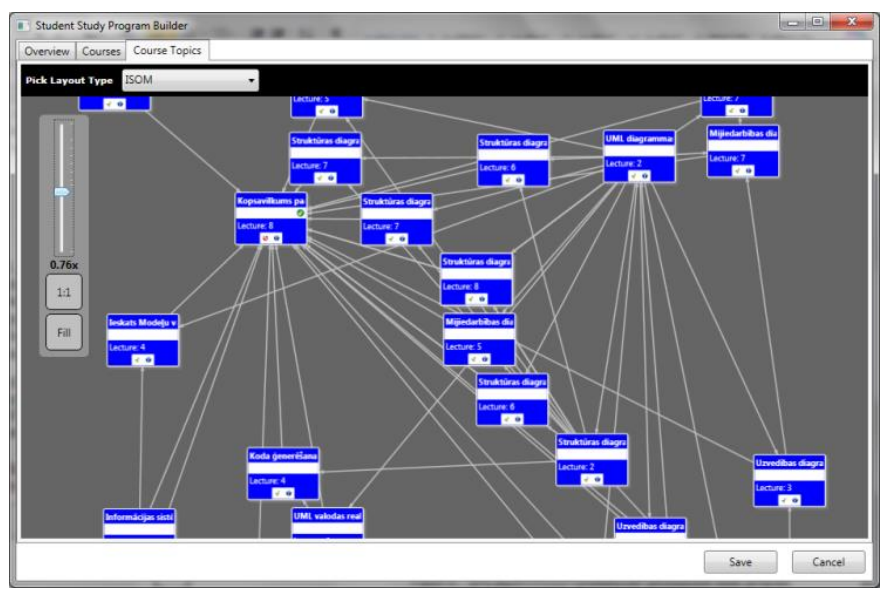

Fig. 6. SPS.StudentStudyprogramBuilder personalized study course acquire $[4,5]$

For the personalized study planning system there are distinguished four groups of users: learners, study programme directors, teachers, study programme administrators.

The next chapter describes SPS structure analysis using structure modelling methods.

\section{STRUCTURE ANALYZE}

The analysis of graph structure is described in several papers [31,32,33]. The authors have chosen to use offered in paper [31] approach of structure analysis - structure modelling because it allows to define the significance of elements which is the main difference from other methods. Structure modelling is the way of topological modelling based on computerized construction and analysis of models, development of knowledge basis, and the use conclusion procedure [31]. It started to develop in mid 1970s and an essential investment in its development has been contributed by 13 researchers of Riga Technical University [31]. It is designed technical system with physically multiple elements for mathematical modelling in the circumstances of imperfect information [31]. In structure modelling there are investigated relationships between structure elements, the importance of elements in functioning of the system as well as the assessment of consequences in case of element elimination [31].

The use of structure modelling approach for the analysis of the structure of study programme, study courses, and concept maps is new its application. So far it was more oriented towards the structure analysis of complicated systems with physically multiple elements, and technical diagnostics. Structure modelling has several methods that allow to perform structure analysis, judge about the role of elements in the structure, and the common characteristics of the structure. One of the methods which is included in the structure analysis is the calculation of the ranks of graph nodes. The acquisition of the ranks allows to define the degree of importance of the node in the common structure. The higher is the rank of the element the closer this element is related to other elements in the structure and the more serious consequences may arise if it is excluded from the structure [31].

In structure modelling it is distinguished between qualitative and quantitative structure analysis [31]. Qualitative analysis defines the importance of the graph nodes. Quantitative analysis uses the distance between the elements defined in the graph theory. As it is essential to define the 
importance of graph nodes in the elaborated framework graphs $G_{1}, G_{2}$ and $G_{3}$, from $G_{1}$ obtaining the most important course in the study programme, from $G_{2}$ the most important themes in the course, and from $\mathrm{G}_{3}$ the most important concepts, the authors use the qualitative analysis of the structure. In order to make qualitative analysis of the structure, ranks should be calculated for the nodes [31]. There are chosen three methods for rank calculations:

- By the local level of the node $\mathrm{R}_{\text {LP. To determine the }}^{1}$ rank of the elements of the local level, element input and output nodes have to be defined, and after that the sum of input and output nodes is calculated by which the elements are ranked.

- By the number of routes in the graph which contain the

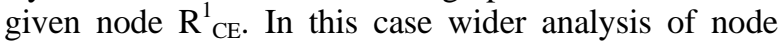
mutual relationship is carried out, stating in how many different routes the node is included. In order to do that, first is stated the set of all routes between input and output nodes. After that the number of routes containing the given node is calculated. The obtained number of routs for each node is divided with total number of routes found. The highest rank is given to the nodes with the greatest value which is obtained dividing the number of routes for each node to the total number of routes in the graph. The rank $\mathrm{R}_{\mathrm{CE}}^{1}$ shows the structural importance of the node, and it reflects in how many learning scenarios the course, topic or concept is included.

- By the number of attainable nodes $\mathrm{R}_{\mathrm{CE}}^{2}$. In this case there are taken into account all routes that make output from node, but the routes making input into the node are not taken into account. In order to find the rank according to the number of achievable nodes, in the matrix line of attainability all the elements are added and the attainability component is obtained, which afterward is divided to total number of nodes in the graph [31]. The greater is the value, the higher is the rank.

To calculate the element structural significance, firstly the summary ranking $\mathrm{R}_{\text {sum }}$ is calculated:

$$
R_{\text {sum }}(i)=R_{L P}^{1}+R_{C E}^{2}[31]
$$

Secondly, the summary ranks are arranged by places and thus a total rank of elements $R_{\text {tot }}$ is obtained. Then the element's structural significance $\mathrm{N}(\mathrm{i})$ can be calculated:

$$
N(i)=1+\frac{1-R_{t o t}}{R_{\max }},[31]
$$

where N(i) - element's structural significance;

$\mathrm{R}_{\mathrm{tot}}-$ element's total rank;

$\mathrm{R}_{\max }$ - the maximum value of the sum of rank.

To calculate the node structural significance usually there are used two ranks: by the number of routes in the graph and by the number of attainable nodes [31], and the authors offer for calculation of the node structural significance also to include the third rank which is calculated by the local level of the node. If the nodes are ranked according to their local levels, then there are analyzed direct links, but indirect links that are essential in complicated systems, are ignored [31]. Thus the local level analysis in complicated systems is not actual. However, it is different in personalized study planning system where calculation of ranking by the local levels of nodes is essential when it is necessary to analyze the local information of each study course, topic, or concept separately. To calculate the values of node structural significance which is based on 3 rank values, first is calculated the summary rank $\mathrm{R}_{\text {sum }}{ }^{1}$ taking into account 3 ranks.

$$
R_{\text {sum }}(i)^{1}=R_{C E}^{1}+R_{C E}^{2}+R_{L P}^{1}
$$

After that to calculate the values of nodes structural significance $\mathrm{N}(\mathrm{i})^{1}$, that is based on 3 rank value, the following formula is used:

$$
N(i)^{1}=1+\frac{1-R_{t o t}}{R_{\max }},
$$

In order to analyze the study programme and the course topic graph structure in personalized study planning system SPS, ranks are calculated for each element of the graph. This is performed in personalized study planning system SPS tool SPS.StudentsStudyProgramBuilder by going to tab Courses with the mouse cursor showing the course then open the information window (Fig. 7), which shows calculated ranks:

- Rank by the local element level $\mathrm{R}_{\text {LP }}^{1}$ (in Fig. 7 marked as R1);

- Rank by the number of routes in the graph which contain the given node $\mathrm{R}_{\mathrm{CE}}^{1}$ '(in Fig. 7 marked as R3);

- Rank by the attainable number of vertices $\mathrm{R}^{2} \mathrm{CE}$ (in Fig. 7 marked as R2);

- Element's total rank $\mathrm{R}_{\mathrm{tot}}$ (in Fig. 7 marked as Rtot);

- Element's structural significance N(i) (in Fig. 7 marked as $\mathrm{N}$ ).

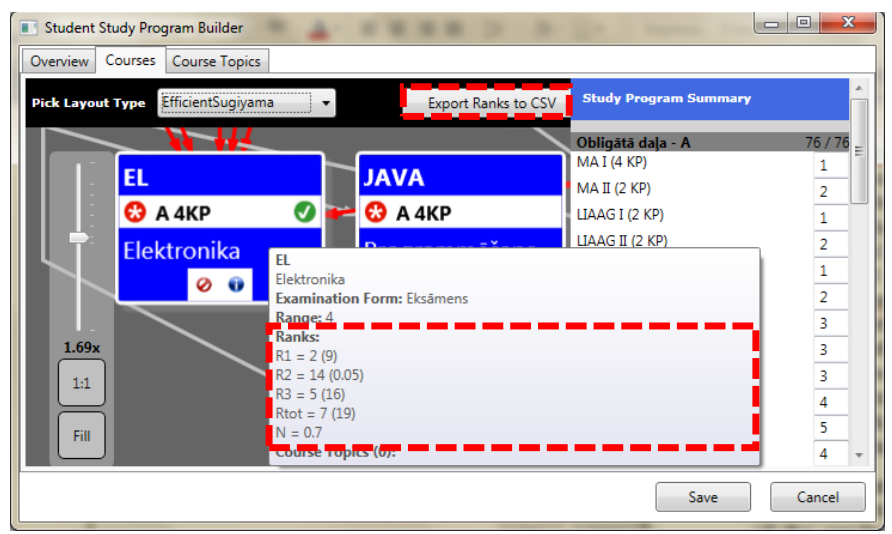

Fig. 7. Personalized study programme course window 
To get an overview of calculated rank values for all courses in Microsoft (MS) Excel file, the option <Export Ranks to $\mathrm{CSV}>$ should be used (Fig. 7).

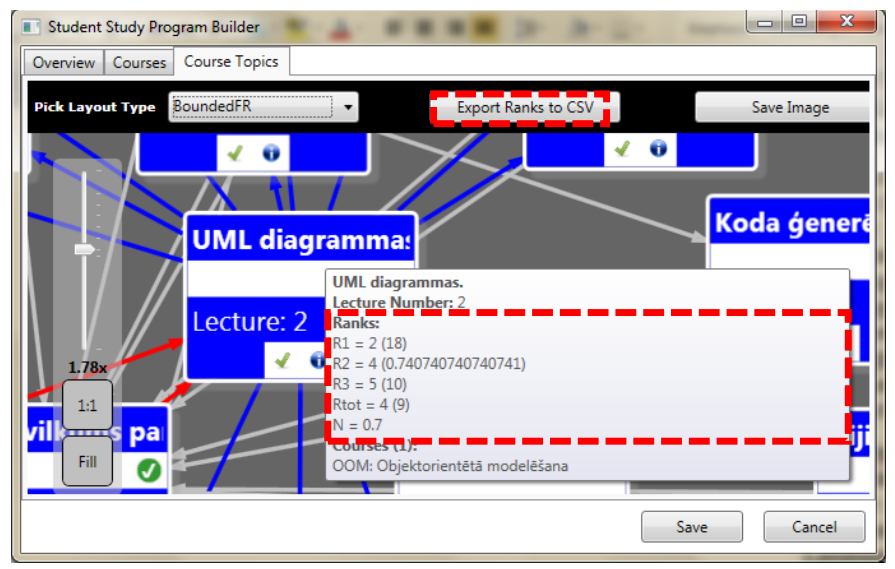

Fig. 8. Personalized study programme study course topic window

In order to analyze the course topics graph structure, similar steps should be performed in Course Topics tab of the tool (Fig. 8). As a result course topic's structural analysis is calculated by the same methods as the structural analysis of study programme graph.

After examining a summary table of structural analysis for the study programme graph of personalized study planning system, it can be concluded:

- By structure analysis of the local levels, it can be seen, that the highest rank is assigned to the course 'Programming', further followed by courses 'Mathematical analysis I' and next courses with equal rank are 'Information system analysis and design' and 'Electronic'. After that other courses follow. Thus are obtained the most significant courses of the study programme by their direct links with other courses. It means also great concentration of learners mastering these courses hence it is advisable to divide such courses into smaller groups so that such courses are not overloaded with too big number of learners. The exclusion of courses with the highest rank from the graph threatens the realization of the study programme because such study courses are prerequisites for other courses. If the learner does not master or masters badly courses with high ranking value, he/she will not possess the necessary knowledge for mastering the related courses.

- Calculating the ranks by the number of routes in the graph which contains the given node, it could be concluded that the higher is the rank, in more learning routes the course is included. Study courses which are included most in different learning routes are 'Basis of Computer Sciences', 'Mathematics Analysis I', 'IS Analysis and Design', and 'Intellectual Network and Computer Telephony'. With equal ranking values follow 'Electronics' and 'Data Processing Systems'. Using the given rank calculation type, higher ranks are obtained by output of the system or their closest predecessors, this statement is valid with courses 'Electronics' and 'Data Processing Systems'. If the learner does not master or masters badly these courses, he/she will not possess the necessary knowledge for mastering the whole study route. If the programme director want to exclude any high ranking course then it is advisable to analyze the whole study route before making decision.

- When analysing the programme graph structure by the number of attainable nodes, the most important courses are 'Basis of Computer Sciences', 'Programming' and with the same rank value follow courses 'Mathematical Analysis I' and 'Mathematical Analysis II'. After that other courses follow. This rank allows to identify the learning routes for mastering the study plan which is out-going from the study course, thus determining the course branching. The higher is the rank for the course the more essential is the role of it in the mastering other courses that are included in the route of this course. If the learner masters insufficiently or does not master at all the courses which have high ranks by the number of attainable nodes, then he/she cannot reach the study programme learning outcomes. High rank by the number of attainable nodes allows to conclude that the learner has to master the course carefully because that influences mastering the other courses. It is advisable to divide the learners into smaller groups in full-time studies to help the learner to master such course and so that the lecturer could work in closer contact with learners. It is advisable to attract substitute lecturers who can substitute the main lecturers of the course if needed and thus ensuring continuous knowledge transfer to the learners. In training systems it is advisable to revise the content of those study courses which have high ranks by the number of attainable nodes and offer additional examples to ensure mastering the course on required quality.

- The total rank sums up $\mathrm{R}_{\mathrm{CE}}^{1}$ and $\mathrm{R}_{\mathrm{CE}}^{2}$, in resulting assessment a total importance of the node. Assessment of the results of the elements total rank, the most important courses are 'Programming', 'Mathematical Analysis I' and courses of the same rank value followed 'Mathematical Analysis II' and 'Basis of Computer Sciences'. It is advisable that study program's directors determine those courses as compulsory mastered courses and the learners have to obligatory include them in their study programme. Consequently, if the study program's director wants to replace these courses with other courses, he/she needs to analyse the next level course topic correlation to the new course to integrate the most important current topics of the course.

The structural significance value of nodes $\mathrm{N}(\mathrm{i})^{1}$ is calculated using the ranks by local levels, by the number of routes in the graph and by the number of attainable nodes. When compare the calculated structural significance value of nodes by two ranks (N(i)), with the calculated structural significance value of nodes by three ranks $\left(\mathrm{N}(\mathrm{i})^{1}\right)$, there is observed the difference in the results. According to N(i) ${ }^{1}$ the 1 st place is shared by the course 'Basis of Computer Sciences', 
which according to $\mathrm{N}(\mathrm{i})$ also is in the 1st place, and course 'Mathematics Analysis I', which according to N(i) is in the 2nd place. The significance value of the course 'Mathematics Analysis I' has increased because this course had the second highest rank by local level of nodes. According to $\mathrm{N}(\mathrm{i})^{1}$ in the 2nd place is study course 'Programming' the value of which is increased by two places in comparison with $\mathrm{N}(\mathrm{i})$ calculated value, because this course had the first highest rank by local level of nodes. The 3rd place according to $\mathrm{N}(\mathrm{i})^{1}$ is shared by the course 'Linear Algebra and Analytical Geometry I', which by $\mathrm{N}(\mathrm{i})$ also was in 3rd place, and the course 'Mathematics Analysis II', which by N(i) was in the 4th place. It should be noted that $\mathrm{N}(\mathrm{i})$ and $\mathrm{N}(\mathrm{i})^{1}$ values are similar, and changes of $\mathrm{N}(\mathrm{i})^{1}$ values in correlation to $\mathrm{N}(\mathrm{i})$ influence the calculated rank values by local level. The author of the paper considers that to evaluate the graph structure is more useful by the structural significance value of nodes which are obtained taking into account all three ranking values because, for example, the course 'Electronics' share the 2nd place in rank calculations by local level although in ranking calculation by the number of the routes it ranks the 5th, but in ranking calculation by the number of attainable nodes it is only in 14th place. In order to determine the structural significance of this course it is important to know not only in how many routes this course has been included or how many different routes are possible from this course but it should be taken into account with how many courses this course is directly linked. Every calculation of node rank has its own meaning, but to obtain the structural significance value of node it is necessary to take into account all 3 ranks. Accordingly structural significance values of nodes, based on 3 ranks are calculated also for the study course structure graph $\mathrm{G}_{2}$ and for the concept map $\mathrm{G}_{3}$.

The calculation of the structural significance value in study programme graph $G_{1}$ helps to divide the study courses according to the parts of the programme, i.e. study courses with higher structural significance values can be added to part A, with low structural significance values to part $\mathrm{C}$, and the rest of the remaining courses that are in the middle add to part $\mathrm{B}$. In order to determine the limits of how many courses to include in each part of the programme, the volume of ECTS can be taken into account.

Examining the structure analysis summary (Annex 1) personalized learning planning system programme course topic graph shows that:

- By structure analysis of the local levels, it can be seen that the highest rank is assigned to the topic 'Overview of the course object-oriented modelling', 'UML diagrams', 'Structure diagram: The Class diagram' and with equal rank values follow 'Unified Modelling Language - UML' and 'System dynamic model'. After that other course topics follow. Exclusion of the topic of the highest rank from the graph may expose the implementation of the course.

- Calculating the ranks by the number of routes in the graph which contains the given node, the highest ranking values are assigned to those topics that are most often included in the routes mastering different topics. Most often the following topics are included in different learning routes: 'Overview of the course object-oriented modelling', 'Introduction into Object-Oriented Modelling', 'Unified Modelling Language - UML', 'UML possibilities in IS design', and 'UML diagrams'. Using this type of ranking calculation, higher ranks obtain the output of the system and their closest predecessors. That has been proved also in this case: the topic with the highest rank is at the top.

- Analyzing the study course topic's graph structure by the attainable number of nodes, authors can conclude that the most important topics are 'An introduction to object-oriented modelling', 'Unified Modelling Language - UML', 'UML opportunities in development of information system', 'UML diagrams', 'Structure diagram: Class diagram'. Further follow other topics.

- Assessing the results according to the elements' total rank, the most important topics are 'An introduction to object-oriented modelling', 'Unified Modelling Language - UML', 'UML diagrams', 'UML opportunities in development of information system', 'Structure diagram: The class diagram'. If from the study programme is excluded any study course and instead is introduced a new one or a new course is introduced additionally then, in order to perform correct correlation with other courses, the mutual correlation of the new course topics should be carried out against topics of other courses.

The determination of the most significant elements in graph $\mathrm{G}_{2}$ is needed to help the lecturer make decisions about what topics include for the exam. The study course includes many topics; all cannot be included in the exam thus the determination of the most significant topics helps the lecturer to make the final decision which topics to include in the exam. When preparing the exam issues, the lecturer can assign for each exam issue points that form the evaluation, and in this case the determination of the most significant elements helps the lecturer to make the decision what points to assign to each issue, the most of the points assigning to the most significant topics. The determination of the most significant topics helps the lecturer prepare the study material because the lecturer may pay more attention to the topics which have high significance. That does not mean that rest of the topics are neglected.

For the analysis of the concept map structure there are used concepts of the topic 'Class Diagram Components'. Reviewing the summary table of the structure analysis, it can be concluded:

- Performing the structure analysis by local levels the highest rank is calculated for the concept 'Types of Links', that means that this concept has most direct links with other concepts. The next significant concepts by local levels are with equal values 'Class' and 'Cardinality', followed by 'Visibility' and with equal ranking values 'Links', 'Operations' and 'Attributes'.

- Calculating the ranks by the number of routes which contain the given concept, the highest ranking values are for the concepts 'Packages', 'Links', 'Class', 'Types of Links', and 'Operations'. 
- Analyzing the structure of the study course topic graph by the number of attainable nodes, most routes are possible from the concepts 'Packages', 'Links', 'Types of Links', 'Class', and 'Cardinality'.

- Evaluating the results by the structural significance, the first most significant concepts are ranked as follows: 'Packages', 'Links', then with equal values are 'Types of Classes' and 'Class', followed by 'Cardinality'. These are five the most significant concepts. In order the learner can properly master the knowledge on topic 'Class Diagram Components', it is compulsory to master the most significant concepts in the structure. Assessing the knowledge of the learner when comparing the concept map created by the learner to the concept map defined by the lecturer, it is advisable to take into account the significance of the nodes, that means, that more points in the assessment are given if the learner has correctly identified significant concept and its correlation to other concepts than less significant concept.

In order to determine the significance of nodes for study programmes, courses or topics it is possible to use the method of structural modelling which justifies making definite decisions about changes in the study programmes, courses, and topics for both the learner and the administrative employee of the institution.

\section{CONCLUSIONS}

The authors previously had to carry out research on the personalized planning of studies on graph-based framework and it is realized by the tutoring module of intelligent tutoring system. Based on described graph-based framework, SPS prototype of personalized study planning has been developed which allows the learner to design the study programme using the graph. In this article the authors describe the use of structure modelling methods to analyze personalized study planning structure based on graph framework. To carry out the qualitative analysis of the structure, ranks are calculated for its nodes. The use of structural modelling approach to analyze the structure of study programme, study courses, and concept maps is a new application of it. So far it was mainly oriented to analyze the structure of complicated systems with physically multiple elements, and technical diagnostics. In structure modelling when obtaining the ranks, the total rank is taken into account not each separately, but in this paper each rank is analyzed separately, because each has its role in the structure analysis. The authors offer also a new solution for the calculation of the structural significance values of the nodes, using 3 ranks: by local levels, by the number of the routes in the graph, and by the number of attainable nodes.

\section{REFERENCES}

[1] Rollande R., Using graph for tutor module construction of intelligent tutoring system, 4th International Conference: Information Society and Modern Business, The Role of Regional Centers in Business Development, Ventspils, Latvia, pp. 39-48, 2009.

[2] Grundspenkis J., Rollande R., Graph based framework for personalization of education process realized by the tutoring module of intelligent tutoring system, Proceeding of The International Conference «Perspectives in Business Informatics Research», 2nd International Workshop on Intelligent Educational Systems and Technology- enhanced Learning (INTEL-EDU 2011), Riga, Latvia, pp. 216 - 225, 2011.

[3] Rollande R., Grundspenkis J., Representation of study program as a part of graph based framework for tutoring module of intelligent tutoring system, Proceedings of The Second International Conference on Digital Information Processing and Communications (ICDIPC 2012), Klaipeda, Lithuania, pp. 108-113, 2012.

[4] Rollande R., Grundspenkis J., Graph based framework and its implemented prototype for personalized study planning, The Second International Conference on E-Learning and E-Technologies in Education (ICEEE2013), Lodz, Poland, pp. 137 - 142, 2013.

[5] Rollande, R., Grundspenkis, J., Mislevics, A., The use of structural modelling methods for analysis of personalized study planning. IEEE Technically Co-Sponsored Science and Information Conference 2014 (SAI), pp. 921 - 926, London, UK, 2014.

[6] Ministry of Environmental Protection and Regional Development, Latvia 2030, 2008. Available: http://www.latvija2030.1v/upload/latvija2030_lv.pdf. [Accessed: 25.03.2013].

[7] The Council Of The European Union, Council conclusions on the modernisation of higher education, Official Journal of the European Union, pp. 36-41, 2011.

[8] The Latvian Parliament, Education Law, Latvijas Vestnesis, Riga, 1998.

[9] The Council Of The European Union, Council Conclusions on investing in education and training - a response to 'Rethinking Education:Investing in skills for better socio-economic outcomes' and the '2013 Annual Growth Survey', Official Journal of the European Union, pp. 5-8, 2013

[10] Cabinet of Ministers, About the program «Information and communication technologies for the quality of education 2007.2013.gadam», Latvijas Vestnesis, Latvija, 2006.

[11] Finland Ministry of Education and Culture, Education and Research 2011-2016, Government, Finland, 2012.

[12] Geer R., Sweeney T., Students' Voices about Learning with Technology, Journal of Social Sciences, vol. 8, no. 2, pp. 294, 2012.

[13] S. Kabicher and R. Motschnig-Pitrik, «Coordinating Curriculum Implementation Using Wiki-supported Graph Visualization», $9^{\text {th }}$ IEEE International Conference on Advanced Learning Technologies. ICALT 2009, Riga, 2009.

[14] P. Gestwicki, «Work in progress - Curriculum visualization», Proceedings of the 38th. Annual Frontiers in Education Conference, Saratoga Springs, NY, 2008.

[15] P. Gestwicki and A. Toombs, «Poster: Design and evaluation of an interactive curriculum visualization system», VisWeek 2010, Salt Lake City, USA, 2010.

[16] R. Zucker, «ViCurriAS: a curriculum visualization tool for faculty, advisors and students», Journal of Computing Sciences in Colleges, pp. 138-145, Vol. 25 , Issue 2, 2009.

[17] T. Auvinen, «Curriculum Development Using Graphs of Learning Outcomes», First EUCEET Association Conference New Trends and Challenges in Civil Engineering Education, Patras, Greece, 2011.

[18] R. Nkambou, C. Frasson and G. Gauthier, «A new approach to ITScurriculum and course authoring: the authoring environment», Computers \& Education, Vol. 31, No. 1, pp. 105-130, august 1998.

[19] R. Nkambou, G. Gauthier and C. Frasson, «CREAM-Tools: An authoring environment for curriculum and course building in an intelligent tutoring system», CALISCE '96 Proceedings of the Third International Conference on Computer Aided Learning and Instruction in Science and Engineering, London, UK, 1996.

[20] R. Nkambou, M.-C. Frasson and C. Frasson, "Generating courses in an intelligent tutoring system», 1996.

[21] R. Nkambou, C. Frasson and G. Gauthier, «CREAM-Tools: An authoring environment for knowledge engineering in intelligent tutoring systems», In Authoring Tools for Advanced Technology Learning Environments, Springer, Netherlands, pp. 269-308, 2003.

[22] Microsoft, «.NET Framework» [Online]. Available: http://msdn.microsoft.com/en-US/vstudio/aa496123.aspx. [Accessed 02.05.2013]. 
[23] Microsoft, «.NET Downloads, Developer Resources \& Case Studies» [Online]. Available: http://www.microsoft.com/net/. [Accessed 02.05.2013].

[24] Microsoft, «Windows Presentation Foundation» [Online]. Available: http://msdn.microsoft.com/en-us/library/vstudio/ms754130.aspx. [Accessed 02.05.2013].

[25] Microsoft, «Visual Studio LightSwitch» [Online]. Available: http://msdn.microsoft.com/en-us/vstudio/ff796201.aspx. [Accessed 02.05.2013].

[26] Microsoft, «SQL Server 2012 Express LocalDB» [Online]. Available: http://msdn.microsoft.com/en-us/library/hh510202.aspx. [Accessed 02.05.2013].

[27] Microsoft, «SQL Server Editions» [Online]. Available: http://www.microsoft.com/sqlserver/en/us/editions.aspx. [Accessed 02.05.2013].
[28] Microsoft, «Visual Studio 2012» [Online]. Available: http://msdn.microsoft.com/en-us/library/vstudio/dd831853.aspx [Accessed 02.05.2013].

[29] Microsoft, «QuickGraph, Graph Data Structures And Algorithms for .NET» [Online]. Available: http://quickgraph.codeplex.com/. [Accessed 02.05.2013].

[30] Microsoft, «Graph\#» [Online]. Available: http://graphsharp.codeplex.com/. [Accessed 02.05.2013].

[31] J. Osis, J. Grundspenkis and Z. Markovics, Complex heterogeneous systems topological modelling, Riga: Riga Technical University, 2012.

[32] Nikolaev V., Bruk V. M., Sistemotechnika: metody i prilozhenija, Leningrad: Machinostrojenie, 1985.

[33] Nečiporenko V. I., Strukturnyj analiz sistem: effektivnost'i nadežnost'., Moskva: Sovetskoe radio, 1977.

Annex 1

TABLE I. STRUCTURE ANALYSIS SUMMARY TABLE OF THE COURSE 'OBJECT-ORIENTED MODELLING’

\begin{tabular}{|c|c|c|c|c|c|c|c|c|c|c|}
\hline Title of the course topics & $\begin{array}{c}\mathbf{R}_{\mathbf{L P}}^{1} \\
\text { value }\end{array}$ & $\begin{array}{r}\mathbf{R}_{\mathrm{LP}}^{1} \\
\text { rank }\end{array}$ & $\begin{array}{c}\mathbf{R}_{\mathrm{CE}}^{1} \\
\text { value }\end{array}$ & $\begin{array}{l}\mathbf{R}_{\mathrm{CE}}^{1} \\
\text { rank }\end{array}$ & $\begin{array}{c}\mathbf{R}^{2}{ }_{\mathrm{CE}} \\
\text { value }\end{array}$ & $\begin{array}{l}R_{C E}^{2} \\
\text { rank }\end{array}$ & $\mathbf{R}_{\text {sum }}$ & $\mathbf{R}_{\text {tot }}$ & $\mathbf{N}(\mathbf{i})$ & $\mathbf{N}^{1}(\mathbf{i})$ \\
\hline Introduction to object-oriented modeling (OOM). & 4 & 5 & 22 & 2 & 0,963 & 1 & 3 & 1 & 1 & 1 \\
\hline Unified Modeling Language - UML. & 6 & 4 & 19 & 3 & 0,8148 & 2 & 5 & 2 & 0,9 & 0,96 \\
\hline UML possibilities in Information Systems (IS) design & 4 & 5 & 11 & 4 & 0,7778 & 3 & 7 & 3 & 0,8 & 0,89 \\
\hline UML diagrams. & 18 & 2 & 10 & 5 & 0,7407 & 4 & 9 & 4 & 0,7 & 0,93 \\
\hline Overview of the course object-oriented modelling & 23 & 1 & 23 & 1 & 0,037 & 10 & 11 & 5 & 0,6 & 0,89 \\
\hline Structure diagram: Class diagram. & 12 & 3 & 6 & 6 & 0,6296 & 5 & 11 & 5 & 0,6 & 0,85 \\
\hline The system dynamic model. & 6 & 4 & 5 & 7 & 0,2593 & 6 & 13 & 6 & 0,5 & 0,81 \\
\hline Behavior diagram: Activity diagram. & 4 & 5 & 3 & 8 & 0,1481 & 7 & 15 & 7 & 0,4 & 0,78 \\
\hline UML implementation environmt. & 4 & 5 & 2 & 9 & 0,1111 & 8 & 17 & 8 & 0,3 & 0,74 \\
\hline Interaction diagram: Interaction overview diagram. & 4 & 5 & 2 & 9 & 0,1111 & 8 & 17 & 8 & 0,3 & 0,74 \\
\hline IS design using object-oriented approach. & 3 & 6 & 1 & 10 & 0,1111 & 8 & 18 & 9 & 0,2 & 0,7 \\
\hline Interaction diagram: Sequence diagram. & 3 & 6 & 1 & 10 & 0,0741 & 9 & 19 & 10 & 0,1 & 0,67 \\
\hline Structure diagram: Component diagram. & 3 & 6 & 1 & 10 & 0,0741 & 9 & 19 & 10 & 0,1 & 0,67 \\
\hline Structure diagram: Object diagram. & 3 & 6 & 1 & 10 & 0,0741 & 9 & 19 & 10 & 0,1 & 0,67 \\
\hline Behavior diagram: State Machine diagram. & 3 & 6 & 1 & 10 & 0,0741 & 9 & 19 & 10 & 0,1 & 0,67 \\
\hline Behavior diagram: Use - Case diagram. & 3 & 6 & 1 & 10 & 0,0741 & 9 & 19 & 10 & 0,1 & 0,67 \\
\hline Code generation options. & 3 & 6 & 1 & 10 & 0,0741 & 9 & 19 & 10 & 0,1 & 0,67 \\
\hline Insight into the Model Driven Architecture - MDA & 3 & 6 & 1 & 10 & 0,0741 & 9 & 19 & 10 & 0,1 & 0,67 \\
\hline Interaction diagram: Collaboration diagram. & 3 & 6 & 1 & 10 & 0,0741 & 9 & 19 & 10 & 0,1 & 0,67 \\
\hline Structure diagram: Deployment diagram. & 3 & 6 & 1 & 10 & 0,0741 & 9 & 19 & 10 & 0,1 & 0,67 \\
\hline Structure diagram: Package diagram. & 3 & 6 & 1 & 10 & 0,0741 & 9 & 19 & 10 & 0,1 & 0,67 \\
\hline Structure diagram: Composite structure diagram. & 3 & 6 & 1 & 10 & 0,0741 & 9 & 19 & 10 & 0,1 & 0,67 \\
\hline Interaction diagram: Timing Diagram. & 3 & 6 & 1 & 10 & 0,0741 & 9 & 19 & 10 & 0,1 & 0,67 \\
\hline Structure diagram: Profile diagram. & 3 & 6 & 1 & 10 & 0,0741 & 9 & 19 & 10 & 0,1 & 0,67 \\
\hline Basic concepts of object-oriented modeling. & 2 & 7 & 1 & 10 & 0,0741 & 9 & 19 & 10 & 0,1 & 0,63 \\
\hline A brief insight into the history of the OOM. & 2 & 7 & 1 & 10 & 0,0741 & 9 & 19 & 10 & 0,1 & 0,63 \\
\hline Object-oriented modeling techniques. & 1 & 8 & 1 & 10 & 0,0741 & 9 & 19 & 10 & 0,1 & 0,59 \\
\hline
\end{tabular}

